\title{
Intragroup accounts of teenage motherhood: a community based psychological perspective
}

\author{
Received November 1996; accepted duly 1997
}

Using community based and women-centred perspectives, this study explored experiences of unplanned motherhood during adolescence. Ten African teenage mothers from a semi-rural area in KwaZulu-Natal volunteered to meet once a week for eight weeks to discuss their experiences of pregnancy and motherhood. The findings are discussed in the context of the effect of teenage motherhood on self, on family and peer relationships, traditional Zulu customs, and community support. Current relationships with partners and concerns about the future are also reported. The results indicate the need for school-based programmes and parent groups for adolescent mothers that will enhance their ability to examine options with a view to establishing a trajectory towards better life outcomes. Community health workers were also identified as resource personnel for enabling teenage mothers in rural and semi-rural areas to cope with their concerns and develop a way of understanding them.

\section{[*] To whom correspondence should be addressed}

The importance of promoting women's health is gaining recognition both nationally and internationally. The Fourth United Nations World Conference on Women, held in Beijing in September 1995, was a watershed for placing women's issues prominently on the agenda. The Platform of Action (POA) which arose out of this conference is a consensus document which identified women's health as a critical area of government policy. The governments of 189 countries, including South Africa, accepted the POA recommendations. The importance of women's health is also enshrined in South Africa's constitution (Section 27) as adopted by the Constitutional Assembly on 8 May 1996. Underpinning the provision of quality health care to women, as highlighted in the objectives of the Beijing POA, and in the South African government's national reconstruction and development programme (African National Congress, 1994), is the need to promote policy-relevant research on teenage pregnancy and. motherhood. Of central importance in this process is the need to strengthen preventive programmes that promote ado' lescent well-being. Despite the importance of, and attention focused on teenage pregnancy and motherhood in South Africa, relatively little policy-relevant research on adolescent childbearing is being undertaken.

Previous research on teenage pregnancy and motherhood initiated in South Africa has in the main focused on issues of obstetric concerns (Loening, 1992; Rip, Keen \& Woods, 1986), and on the factors associated with teenage pregnancy (AbdoolKarim, K.S., Abdool Karim, Q., PrestonWhyte \& Sankar, 1992; Buga, Amoka \& Ncayiyana, 1996; Craig \& Richter-Strydom, 1983; Mayekiso \& Twaise, 1993; Ncayiyana, 1992; O'Mahony, 1987; Preston-Whyte \& Zondi, 1992). With few exceptions (e.g. Craig \& Richter-Strydom, 1983; Preston-Whyte \& Zondi, 1992), the existing research has overwhelmingly used a positivist problem-oriented approach (e.g. Mayekiso \& Twaise 1993; O'Mahony, 1987). Implicit within this approach is the belief that pregnancy and 
motherhood during the adolescent years could best be understood and explained with reference to adolescent personal factors (e.g. the adolescent's sexual maturation and sexual behaviour, factual knowledge about fertility, conception, and contraception, parental involvement in imparting sexual knowledge to adolescents, etc.). This effectively has meant that the adolescent is treated as the problem, and the adolescent's parents (on account of their apparent failure to impart sexual information to their children) as the 'agents' responsible for creating the problem. Following this view, the-positivist problem-oriented approach has lent itself to moral or prescriptive messages favouring sexual abstinence during the teenage years (Bukatko \& Daehler, 1995).

Discussions of teenage pregnancy cannot however be understood in isolation from the structural inequalities between people and the power and cultural differentials which shape people's realities. Teenage pregnancy in the context of African[1] communities, for example, has been partly linked to cultural values about womanhood and fertility, and to the minimal negative repercussions either on the part of parents or the community at large following the birth of a child to an adolescent girl (Ncayiyana, 1992; Preston-Whyte \& Zondi, 1992). Tolerance of adolescent sexuality and teenage births as a factor associated with teenage pregnancy has also been reported among certain ethnic groups in Kenya (Mutuku \& Mutiso, 1994), India (Schlegel \& Barry, 1991), and Polynesia (Muuss, 1996).

Cultural values and norms are among multiple factors associated with teenage pregnancy. Poverty, unemployment, inadequate and overcrowded housing, the disruption and dislocation of everyday life resulting from apartheid labour and social practices, the lack of community recreational facilities, as well as issues of patriarchal power and domination are consistently reported concomitants of teenage pregnancy (Levett, 1994; Magwaza \& Shezi, 1994; PrestonWhyte \& Allen, 1992; PrestonWhyte \& Zondi, 1992). For example, Magwaza and Shezi (1994), in an unpublished study on teenage pregnancy in a semirural African context, report that a significant number of the teenage girls they interviewed cited access to resources (e.g. transport and money for basic necessities) as a reason why they consented to sex with older men. Of their sample, $55 \%$ also indicated that some of their sexual encounters were coerced. These authors argued that within African communities men control most resources which are then used by some as a means to coercing teenage girls to enter into a pseudo-consensual sexual relationship.

We argue that discussions of teenage pregnancy and motherhood must make apparent that the phenomenon with which we are dealing is a complex social issue. Research which examines variables in isolation from each other, is unable to address these complex social issues precisely because it individualises the problem of teenage pregnancy and motherhood and depoliticises the role played by society in the development of adolescent distress.

Studies, primarily from the United States and Britain, which have paid attention to the social and psychological impact of teenage motherhood have generally taken two forms: firstly, there are descriptive accounts of the experiences of mothering during the teenage years; and secondly, there are studies which have explored the efficacy of self-help organisations and other forms of social support for reducing or alleviating the difficulties of teenage motherhood.

Research on the immediate and long-term adjustment to mothering among teenage girls suggests that mothering is stressful. The consequences of teenage motherhood include low personal esteem and personal efficacy (Thompson \& Peebles-Wilkins, 1992), higher risk for psychological distress (Bierman \& Streett, 1982), limited educational and occupational achievements (de Anda \& Becerra, 1984), and loneliness (Fine \& Pope, 1982).

More recent studies highlight the role played by the availability or quality of support offered and its effects on the teenage mother's psychological well-being. The general picture to emerge from this research is that social support may be beneficial, at times inconsequential, and occasionally detrimental (Chen, Telleen \& Chen, 1995; Davis \& Rhodes, 1994; Richardson, Barbour \& Bubenzer, 1991; Thompson \& Peebles-Wilkins, 1992). The work of Thompson and PeeblesWilkins (1992) is particularly interesting in that it is one of the few research studies to focus on the relative merits of societal support for black teenage mothers from disadvantaged communities. In this regard, Thompson and Peebles-Wilkins report that informal assistance from friends or peers increased the adolescent mother's level of distress. However, support from a male partner, frequent contacts with a case worker, and participation in self-help groups (e.g. teenage parent groups and single parent groups) tended to relieve the mother's psychological distress. Interestingly, the effects of church attendance and social clubs on psychological distress were negligible. These findings clearly illustrate the importance of self-help networks as intervention strategies for the empowerment of disadvantaged and at-risk groups.

Current policy developments in South Africa indicate a shift towards community mental health care (Committee for Mental Health and Substance Abuse, 1995). Central to this approach is the 
need for resources to address the psychiatric, as well as psycho-social well-being of individuals and communities. However, given the resource problems so prevalent in South Africa, as well as the unlikelihood of extra resources being made available for mental health care (Petersen,

Bhagwanjee, Parekh, Paruk \& Subedar, 1996), it is clear that existing resources would have to be used. This is particularly true for the rural and semi-rural areas of KwaZulu-Natal where health and welfare services are scarce. In the context of few resources, the use of self-help organisations could prove to be viable alternatives for mental health delivery at a community level.

This study on teenage motherhood was initiated by researchers who were part of the Community Mental Health Programme located at the University of Durban-Westville. The site of the study was KwaDedangendlale, a semi-rural area approximately $40 \mathrm{~km}$ from Durban. During $1994 \mathrm{a}$ community based needs assessment identified teenage pregnancy as one of the more serious social problems confronting the community and for which the community requested assistance. The present study was therefore undertaken with the view to recommending an appropriate model of service delivery to address this specific concern. More specifically, the aims of the present study were: firstly, to examine the experience of unplanned pregnancy and motherhood within an African community from a woman-centred perspective (i.e. an examination of the topic from the perspective of the woman's own experiences and values); and secondly, to recommend intervention programmes that could be developed, implemented and sustained within a semi-rural context.

\section{Method}

\section{Site}

The population of KwaDedangendlale is estimated to range from between 55000 to 75000 people (Pitt, 1994; Stavrou \& Luckin, 1992). Like much of KwaZulu-Natal, KwaDedangendlale is semi-rural, with low density housing scattered across a hilly terrain. Access to basic services such as water, sanitation, electricity, roads and telephones is limited (Petersen et al., 1996). The formal health services comprise a single primary health care clinic with mobile clinics that visit various points in the areas. Welfare services are similarly limited. A significant portion of the school-aged population are in under-resourced schools with high drop-out and failure rates. The rate of unemployment is high with the majority of the population living below the poverty datum line.

Participant selection The participants were selected with the assistance of a community health worker who had expressed an interest in the project. The criteria for selection were: (a) participants had to be between the ages of 15 and 21; (b) their babies had to be between 12 months to 36 months of age; (c) participant mothers had to have been in their teens at the time of birth; and (d) participants had to be attending school at the time of the study.

\section{Participants}

Potential participants who met the criteria were contacted by the community health worker and were asked to attend a meeting where details pertaining to the project would be outlined. Ten teenage mothers attended the meeting and all were keen to participate in the group. Since the community health workers in the KwaDedangendlale area are attached to specific geographical zones, the ten women who volunteered were all enrolled at the same school and they lived in the same area. The participants ranged in age from 16 to 20 years with a mean age of 19 years. Participants were of low socio-economic status, unmarried, and had only one child (between one to two years of age).

\section{Procedure}

The facilitators of the group sessions were two women, both in their early twenties. The facilitator, a research assistant in the Community Mental Health Programme, was a first-language Zulu speaker and the co-facilitator was a postgraduate student with basic Zulu conversational skills. The community health worker who assisted in the recruitment process was also present at the sessions.

\section{Data collection}

Data were collected by means of focus group discussions which were held once a week for eight weeks, with each meeting lasting about an hour and a half. During the first meeting a contract was jointly developed by the participants and facilitators. This contract included agreements to attend group sessions, to respect confidentiality and to lay down the ground rules for the functioning of the group sessions. An outline of the eight .week programme was presented, and participants were informed that the facilitators would plan each session in advance with a view to covering specific themes relating to teenage pregnancy and motherhood. All sessions were conducted in Zulu and were tape recorded with the consent of each of the participants. The sessions also included recreational activities such as games, music and art. Refreshments were provided. 


\section{Data analysis}

After each session the tape recorded discussions were transcribed and translated from Zulu into English for the purposes of analysis. While acknowledging the impossibility of achieving direct equivalence of meaning in translation (Drennan \& Levett, 1996), the researchers strove for authenticity by means of translations done firstly by the fluent same-language facilitator and then by jointly examining the process of interpretation and translation with both facilitators. Ambiguities and problems were-then discussed with a fluent Zulu and English speaker who was not directly involved with the research project.

The transcribed data were analysed using a method of thematic content analysis. Bearing in mind that the process of textual analysis is eclectic with there being no right way of doing it (Cresswell, 1994), each transcript was first analysed into categories of information such as:

- nature and extent of sexual relationships prior to pregnancy;

- affect in relation to the confirmation of the pregnancy;

- reaction of parents and partner;

- level of social support during and after the pregnancy;

- changes, difficulties and concerns in life after pregnancy.

Thereafter, a second level of analysis was conducted to identify themes and patterns across participants. The themes and patterns that emerged are described under the relevant category label. Individual differences and similarities within the group were noted.

\section{Results}

\section{Nature and extent of sexual relationships}

The participants ranged in age from 12 to 17 years when they first engaged in sexual intercourse. Five participants were sexually active before 16 years of age, and three before they were 13 . Six participants reported having had two to three sexual partners prior to their pregnancy. Pressure from 'boyfriends', the need to prove one's affection, and fear of desertion were three frequently expressed reasons for engaging in sexual intercourse. None of the participants stated that they had used any form of contraceptives. The primary reasons given for not using contraception were lack of knowledge about fertility, conception and contraception, as well as resistance from partners. Some of the participants reported that their partners did not approve of the use of condoms, and that they were afraid that if they insisted, they would create the impression that they were 'sleeping around'.

Myths and incorrect information, derived mostly from friends and women care-givers, were quite pervasive in the group. Consider here the following extracts from the group discussions:

I refused [to use contraceptives] because I heard it makes your body jelly-like (Pumi).[ 2]

I did not try contraception because I thought I was still too young and I was never going to get pregnant (Zethu).

I refused [to use contraceptives] because I heard from people [and] also my grandmother that it creates conflict between partners (Zanele).

I heard it caused a lot of discharge and your boyfriend would think you had sex with other men (Sibongile).

Lack of knowledge about traditional methods of practising safe sex was an additional reason for not using contraception. As Ntombi stated:

If I knew about other traditional methods like 'ukusoma' [the woman crosses her legs to prevent the man from penetrating her] I would have opted for such a method; but I did not know how to practice such a method.

Interestingly, the participants in the study perceived the advice on sexual matters from more informed sources from within the community, such as community health workers, as problematic. The community health worker who participated in the group said that she presented teenage girls with the following advice: 
If you enter into a love relationship with a male the intention must not be to make a baby. You must tell the guy that you do not want to have sex with him. Ask him if he loves you or your private part. Even if you use contraceptives the virginity will no longer be there when you marry. The only .thing that you should do is deep kiss and talk about your future.

\section{Confirmation of pregnancy and reaction of significant others}

Most participants reported that they first sensed they might be pregnant when they stopped menstruating. In most instances it took a few months of 'missed periods' before the participants acknowledged the possibility that they could be pregnant. Some participants reported that they were. only marginally convinced of their pregnancies once they began/to experience symptoms such as nausea, vomiting and 'swollen breasts'. For some participants initial feelings of worry and anxiety were replaced at a later stage by rationalisation and denial. Angela, for example, reported that despite the fact that she was experiencing abdominal pains and her 'breasts were getting bigger', she tried to successfully convince herself that because her 'stomach was not getting bigger' she could not be pregnant, It was only six months later when she went to a medical practitioner that her pregnancy was confirmed. Also noteworthy is Anick's poignant account of when and how she discovered she was pregnant:

I did not know I was pregnant until I was in the eighth month. I did not know what it means when one misses her period. Until one Saturday my father said he dreamt that there was someone pregnant in the house and that if there was he was going to chase the person away. That was the last week of the eight month. One morning after the incident I was getting ready for school and I was still naked. My mother saw me and said my breasts were getting too big and also my stomach. She then asked my aunt to check me. My aunt then confirmed that I was pregnant. I hated bread and anything with oil, but I didn't know it was related to pregnancy. After a week I delivered.

On confirmation of the pregnancy most participants reported feeling sad, disappointed, shocked and depressed. Anick said that she felt quite suicidal and Lungile reported that she considered the option of abortion but subsequently changed her mind. Seven of the ten participants had their pregnancies confirmed by a medical practitioner; the other three sought confirmation from relatives.

\section{Reaction of significant others}

Most participants reported that their mothers or. other older women in the house were usually the first to suspect that they were pregnant. When confronted by them the participants' initial reaction was to deny the pregnancy until circumstances (body changes) later forced them to confess. In general, the initial reaction of parents/care-givers was one of shock and anger. This was followed by disappointment over the teenage mother's apparent failure to live up to their aspirations and expectations, and concerns about the family's reputation in the community. The following statements best exemplify these feelings and reactions.

My father and mother were very hurt. My father trusted me and hoped that I would finish school without getting pregnant (Tandi).

She [mother] told me that I spoiled all the plans she had for my future since I was in Std 10 (Zethu).

My mother was very hurt. She even cried tears. She said she won't be able to face the community with the shame I brought on her (Lungile).

Fathers of the participants were reported to have expressed their anger and disappointment more visibly than mothers. Two participants reported that their fathers 'hit' and 'chased' them out of the house. An interesting trend which emerged from the discussions was that women care-givers were often 'blamed' by the older men in the family (e.g. fathers and uncles) for not exercising control and discipline and for allowing the teenager to 'fall pregnant'. In spite of these initial reactions, all participants reported that their care-givers eventually displayed tolerance and acceptance, and encouraged them to resume their schooling after the birth of the baby. Consider with regard to the reaction of care-givers the following selection of quotations:

My mother was very hurt. My uncles did not say anything to me. They however blamed my mother and told her that she was not strict with me (Ntombi).

The person that was too disappointed in me was my father... Each time my father used to blame my mother. My mother would then take it out on me (Anick). 
My mother was not so angry. My father was very angry. He said I disappointed him. He hit me and chased me away. On the night he found out I slept outside. He told me that he won't send me back to school because I wasted his money. But as time went on he accepted me. He said after delivery I must go back to school (Zanele).

It appears that the care-givers' general acceptance of the situation may in part be explained by Zulu customs and traditions. All participants reported that they were compensated for their pregnancies by their partner's family. The compensation, referred to as inhlawulo (payment for damages - for the breaking of the hymen) and umgezo (cleansing of bad luck) took the form of money and livestock. Essentially, the compensation was a form of recourse for the care-givers of the teenage mother and a means by which the father of the child acknowledged his share of the responsibility.

With one exception, all sexual partners were unemployed and the majority were still at school. Their initial reaction was one of surprise, dismay, and fear over what their own fathers' reaction would be. The latter was the main cause of anxiety in partners and centred around the fear that their fathers would force them to leave school and begin working so as to assume their share of the financial responsibility of child-care. Three of the participants reported that their partners initially denied that they were the fathers. According to Anick, her partner informed her that 'he was incapable of getting anyone pregnant and that he has a card to prove it'. Pumi reported that her panner claimed to be on a pill that prevented pregnancy and even went so far as to show her the pill! Nonetheless all partners, including those who initially denied any responsibility, eventually accepted their parental status, partially because of their own family's willingness to accept the situation. From a financial point of view, it was reported that the fathers could not provide for the upkeep of the child and that all participants were reliant on financial support from their own families.

\section{Social support}

Social support for teenage mothers was found to be minimal and, if available, was derived mostly from mothers and grandmothers, although not without conflict. As Sibongile explained:

I did not take care of the baby from the beginning. My mother was doing everything for me. The problem I had was that my mother did not even allow me to sleep with the child.

Three participants reported that their child lived with the father's family so as to enable them to continue with their education.

Friends were found to vary in their level of support. Some friends were supportive and encouraged the teenage mother to go back to school, while others no longer expressed a desire to associate with her. Community members were perceived to be quite unsympathetic and often chastised the teenage mothers for having violated Christian religious beliefs.

\section{Changes, difficulties and concerns in life after pregnancy}

Pregnancy changed my life because I am also a parent, and I have the responsibilities of being a parent (Ntombi).

All participants reported considerable changes to their lifestyles after the birth of the child. The dual roles of mother and scholar meant that they had to attend to their child's needs before going to school. Upon their return from school they had to engage in similar child care activities as well as attend to other household chores. According to the participants, these dual roles and multiple functions meant that they had considerably less time to devote to their studies and consequently often lagged behind in their school commitments. This was further compounded by the fact that many of them did not return to school immediately after delivery and in some cases returned only a year to two years after the child was born.

In cases where the child was living with the father's family, the mothers reported that they would visit their child on the weekends and stay over so as to lessen the burden of child care placed on their 'in-laws'. While this arrangement spared them the day-to-day responsibility of child care, they were not altogether exempt from the demands brought about by the birth of a child, and often had to meet these demands at the expense of weekends devoted to their studies. One participant reported feeling quite depressed after childbirth, to the extent that she became asocial, withdrawn, and anti-'boys'. Consider here the following excerpts from the group discussions:

In the mornings I would breastfeed and wash my baby's napkins. After school I did the same thing, that is, wash clothes for the child and bath and feed the child as. well as help my mother in the house. Problem I had was that at school I was left behind in my studies (Sibongile). 
My child stays at his father's place. I go on Fridays to see the child and prepare the things for the following week so that my boyfriend's family would not think I was leaving them to do all the work. I then come back on Mondays-to go back to school (Pumi).

[After pregnancy] I also did not want to mix with people; or be seen by people. I kept indoors most of the time. I hated boys (Nomsa).

As illustrated by the following two excerpts, participants also reported a change in friendship patterns.

Pregnancy did change my life; socially I lost many school friends after the delivery. They did not want to associate with me now that I was a parent (Zethu).

Problems that are associated with taking care of the child are that I can no longer go to parties and visit friends. Another problem is that I also lost contact with my old school friends because I only went back to school two years after my child was born (Tandi).

Many participants had lost contact with their original school friends, either because friends no longer wanted to associate with them or because their cohort had moved on to a higher standard. Consequently, they were forced to make new friends. This, they reported, also presented a problem because the change in their lifestyle meant that they had very little in common with other pupils in their class. It is worth noting that all the participants found the group experience to be extremely valuable in that for the first time they were afforded the opportunity to share their feelings, experiences and concerns, and more importantly, with similar others.

Although the families of the teenage mothers were in general quite supportive, many of the participants reported that they felt the need to be exceptionally welt-behaved in order to compensate for the disappointment that they had caused their parents. As reported by Pumi:

Because I let my parents down I feel that I now have to try my best to be good to make up for it.

All participants expressed the desire to marry the father of their child, although some were concerned that the father would be unfaithful in marriage, or would find another partner before marriage could take place. In both cases this was seen as having a negative impact on the child. Furthermore, while the desire to have more children was a common sentiment reported by the group, fear of a second premarital pregnancy was pervasive. All participants were strongly committed to the future well-being of their children. Embedded in their accounts was the desire to ensure that their children were well-educated so that they could play a meaningful role either in the community or at a broader societal level.

\section{Discussion}

The findings of this study confirmed that the transition to motherhood is accompanied by a number of psychological consequences that place the teenage mothers at risk in terms of later life adjustment. The fact that all the participants met the confirmation of pregnancy with a mixture of disbelief and disappointment suggests that they were far from emotionally, cognitively and socially ready for the prospect of motherhood. The lack of preparedness for motherhood could be attributed in part to a breakdown in traditional Zulu customs and practices in the areas of sexual instruction. As scholarly literature (e.g. Preston-Whyte \& Zondi, 1992; Viljoen, 1994) and anecdotal accounts indicate, among African families of Zulu origin, it was considered customary for the 'facts of life' to be explained to teenage girls. This was done formally, for example, through initiation schools, and informally by older women (e.g. grandmothers and aunts) through stories and tales. In the group discussions it was clear that these traditional practices had lessened in importance over time. Peers and the mass media were now the primary source of sexual knowledge. Information and knowledge gained from these sources were, however, often erroneous and/or distorted and accomplished little in the way of promoting informed attitudes to issues of human sexuality and reproductive health.

This study found that the majority of the participants expressed the desire for more children. Research has shown that delay in subsequent childbearing has been found to be a major predictor of greater success in an adolescent mother's later life (Seitz \& Apfel, 1993). According to this research, adolescent mothers who deliver a second child soon after the first appear to become overwhelmed with their multiple responsibilities and are likely to abandon hope for personal achievement. Based on these findings, it would seem that there is an urgent need in South Africa for postnatal intervention programmes that begin with primiparous adolescents so that subsequent decision making with regard to future child-bearing is based not simply on whether one is married or not (as was the case in the present study) but on the long term 
implications for the adolescent mother's future educational and occupational advancement, as well as considerations for the development of her children.

The participants' descriptions of the reactions and support shown by significant others provide insight into existing assumptions about support networks for African teenage mothers. Previous research indicated that the pragmatic attitude displayed by African care-givers, aided in part by culturally negotiated settlements of reparation and responsibility, had a positive effect on teenage women's adjustment to motherhood (Preston-Whyte \& Zondi, 1992). While the attitude of the care -givers and the reasons thereof were similar, this study suggested that these attitudes did not necessarily reduce the teenage mother's level of psychological discomfort nor her feelings of guilt and personal recrimination. Instead, it obliged the teenage mothers to take on the persona of a dutiful daughter who was compliant and obedient in response to the 'goodwill' extended to her by her care-givers.

A second indication suggesting that not all of the support received from care-givers was positive is the finding that caregivers may at times usurp the mother's role. This was consistent with the literature on this issue. Richardson, Barbour and Bubenzer (1991), for example, identified the care -givers' usurpation of the teenage mother's role as one of the major sources of familial and personal conflict common to teenage parenthood which may lead to psychological distress. They argued that in such cases, school-aged parents may have to fight for authority over the child especially when negotiating differences between grandparents' traditional child-care techniques and more current methods.

On a positive note, the fact that families were willing to play a supportive role in enabling the teenage mother to return to school is reassuring. Education, per se, has been found to play a significant role in influencing the well-being of adolescent mothers. Thompson and PeeblesWilkins (1992), for example, illustrated that black teenage mothers with at least a high school diploma had, on average, fewer psychological distress symptoms, fewer symptoms of depression, and higher self-esteem scores than adolescent mothers with few years of formal education. The effects of education remained strong and persistent even when measures of social support were considered.

The commitment to education on the part of care-givers needs to be contextualised. Within KwaDedangendlale, an area characterised by widespread poverty and unemployment, education offers the only hope to families of improving their situation. The majority of the elderly in the community are unemployed and further lack or have minimal levels of formal education. Hence, it is conceivable that for them hope for a better future lies in their children's education. A child who is well-educated is probably more likely to be employed and therefore better placed to improve the financial well-being of the entire family. This probably explains why care-givers were prepared to make considerable sacrifices and endure hardship to support the teenage mother in her efforts to complete her formal education.

In summary, the findings with regard to familial support for teenage mothers suggest that its effects are not uniformly positive. Rather, the possibility exists that some kinds of support may be beneficial and others counter-productive. Further research is needed to examine the relative importance of different types of. family support and how these impact on the psychological wellbeing of African teenage mothers.

Uncertainty over future interpersonal relationships, economic hardships and lack of peer and community support and understanding were also found to create a stressful environment surrounding the teenage mother, which did little to promote her psychological well-being. The loss of peer support and friendships is of concern, particularly in the light of the heightened importance of the peer group during adolescence (Conger, 1991; Emler \& Reicher, 1995). As Emler and Reicher (1995) state, the peer group is central to the manner in which adolescents find their way in the world. It both allows them to understand their predicament and provides them with the means to act accordingly. The general dislocation of teenage mothers from previously existing social networks (e.g. school friends) because the latter may be dissimilar in present experience and attitudes, highlights the need for new sources of support for teenage mothers. The preferable option would be for support to be provided by similar others which would, among other benefits, provide teenage mothers with appropriate reference groups to compare and evaluate their own performance and functioning as parents.

With regard to the above, it should be noted that the group context was seen as beneficial because it allowed participants to express their fears, worries, and to interact with others facing similar challenges. Several participants stated that this group exercise had been their first opportunity to talk about the negative aspects of their experiences as teenage mothers. Given this, it appears that group work, which combats the problem of isolation and enables supportive 
interaction in a safe context, could be the most appropriate context of counselling and dealing with problems relating to teenage motherhood. That teenage mothers have more in common with each other than they typically realise became evident during the meetings of the peer group.

\section{Conclusion}

It is clear that much needs to be done to facilitate the teenager's adjustment to motherhood. One suggestion is to establish schoolbased programmes for adolescent mothers that equip them with life skills. It is assumed that these programmes will enhance teenage mothers' ability to examine new life options with a view to establishing a trajectory towards better life outcomes. Schoolbased programmes have the potential of reaching a large proportion of high-risk populations and might therefore be a good choice as a service delivery model.

Another suggestion is to run community based peer groups for adolescent mothers. Participation in peer groups can provide an opportunity for teenage mothers to share their experiences and obtain encouragement for parenting, thus facilitating their adjustment to their mothering role. Support from this source could also assist teenage mothers in re-establishing their self-esteem and their identity independent of mothering, and may provide an important vehicle for sustaining peer contact. Moreover, in the South African context where many African children have been denied the opportunity of a formal school education, community based peer group programmes could serve as a useful adjunct to school-based programmes in that they could effectively reach teenage mothers who are not at school.

Finally, the void created by the demise of traditional Zulu customs and practices in the areas of sexual instruction also suggest the need, at a community level, for alternate sources of sex education for children and adolescents. In rural and semi-rural areas, community health workers are well placed to provide this education. Given that community health workers are attached to specific geographical zones and service approximately 100 homes they could effectively reach out to all the youth in the area, particularly those not at school. In order for community health workers to be successful in this regard, it is essential that they be trained in what constitutes effective sexual instruction and on how .best to render advice and assistance.

In summary, this study attempted to combine insights from community mental health and womencentred perspectives. It became clear that in rural and semi-rural areas, community based peer groups and a school-based programme are potentially powerful tools, with community health workers as ideal re-sources, in helping teenage mothers cope with their concerns and develop a way of understanding them. While the feasibility and sustainability of these intervention strategies have yet to be established, this study has to some extent demonstrated their potential value as counselling, therapeutic and educational opportunities. The relevance and urgency of this strategy needs to be acknowledged. For in the words of Nomsa:

Pregnancy did change my life in many' ways; for example, I lost my friends and I also did not want to mix with other people, or be seen by other people. I kept indoors most of the time. I hated boys. It is difficult to cope with the roles of being a student and a mother, but now I am used to it. I wake up at 4.30 in the morning to prepare for the child before I get ready to leave for school. It is indeed difficult to raise a child but I am trying my best and I wish that my child can grow up well and I can provide everything necessary. I also wish that my child takes after me and is intelligent at school. I Want to get married when I have a job and am secured. I do not want more children now. After marriage I have no limit because I will be paying back lobolo - 11 cows [for] 11 children.

Acknowledgements

The authors gratefully acknowledge the assistance of Amanda Shembe and Thirusha Naidu. This research was supported by a grant from the Trust for Health Systems Planning and Development.

Notes

1. The authors acknowledge the 'contentious use of the term 'African'. In the context of the literature reviewed the term African is used in a racial sense, regardless of ethno-linguistic identity. However, in the context of the present study the term African is used to refer to people of Zulu ethnicity.

2. To help preserve confidentiality all references to participants are rendered in pseudonyms.

\section{References}

Abdool Karim, S.S., Abdool Karim, Q., Preston-Whyte, E. \& Sankar, N. (1992). Reasons for lack of condom use among high school students. South African Medical Journal, 82, 107-110.

African National Congress (1994). The reconstruction and development programme: a policy framework. Johannesburg: Umanyano Publications. 
Bierman, B.R. \& Streett, R. (1982). Adolescent girls as mothers: problems in parenting, In I.R. Stuart \& C.F. Wells (Eds), Pregnancy in adolescence.' needs, problems, and management. (pp. 68-79). New York: Van Nostrand Rheinhold.

Buga, G.A.B., Amoko, D.H.A. \& Ncayiyana, D.J. (1996). Sexual behaviour, contraceptive practice and reproductive health among school adolescents in rural Transkei. South African Medical Journal, 86, 523-527.

Bukatko, D. \& Daehler, M.W. (1995). Child development.' a thematic approach. Boston: Houghton Mifflin Co.

Chen, S.C., Telleen, S. \& Chen, E.H. (1995). Family and community support of urban pregnant students: support person, function, and parity. Journal of Community Psychology, 23, 28-33.

Committee for Mental Health and Substance Abuse (1995). Mental Health and Substance Abuse Report. Pretoria: Ministry of Health.

Conger, J.J. (1991). Adolescence and youth.' psychological development in a changing world (4th edition). New York: Harper Collins Publishers.

Craig, A.P. \& Richter-Strydom, L.M. (1983). Unplanned pregnancies among urban Zulu school children: a summary of the salient results from a preliminary investigation. The Journal of Social Psychology, 121,239-246.

Cresswell, J.W. (1994). Research design.' qualitative \& quantitative approaches. Thousand Oaks, California: Sage.

Davis, A.A. \& Rhodes, J.E. (1994). African-American teenage mothers and their mothers: an analysis of supportive and problematic interactions. Journal of Community Psychology, 22, 12-20.

de Anda, D. \& Becerra, R.M. (1984). Support networks for adolescent mothers. Social Case work.' The Journal of Contemporary Social Work, 1, 172-181.

Drennan, G. \& Levett, A. (1996). Translation in psychological research: theoretical and conceptual aspects. Unpublished paper, University of Cape Town, Cape Town.

Emler, N. \& Reicher, S. (1995). Adolescence and delinquency. Oxford: Blackwell Publishers Ltd.

Fine, P. \& Pope, M. (1982). Pregnant teenagers in need of social networks: Diagnostic parameters. In I.R. Stuart \& C.F. Wells (Eds), Pregnancy in adolescence.' needs, problems and management (pp. 80-96). New York: Van Nostrand Reinhold.

Levett, A. (1994). Problems of cultural imperialism in the study of child sexual abuse. In A. Dawes \& D. Donald (Eds), Childhood and adversity: psychological perspectives from South African research (pp. 240-260). Cape Town: David Philip.

Loening, W. (1992). Adolescent pregnancy: a medical perspective on the consequences for mother and child. In S. Burman \& E. Preston-Whyte (Eds), Questionable issues: illegitimacy in South Africa (pp. 77-91). Cape Town: Oxford University Press.

Magwaza, S. \& Shezi, C. (1994). A group perspective on the experience of teenage pregnancy. Unpublished report, The Community Mental Health Project, University of DurbanWestville, Durban.

Mayekiso, T.V. \& Twaise, N. (1993). Assessment of parental involvement in imparting sexual knowledge to adolescents. South African Journal of Psychology, 23, 21-23.

Mutuku, M. \& Mutiso, R. (1994). Kenya: the urban threat for women and children. In C.S. Blanc (Ed.), Urban children in distress: global predicaments and innovative strategies (pp. 217-258).

Switzerland: Gordon and Breach.

Muuss, R.E. (1996). Theories of adolescence (6th edition). New York: Mc Graw-Hill Co, Inc.

Ncayiyana, D.J. (1992). Teenage pregnancy in Transkei: perspectives of a devil's advocate.

Transkei Medical Quarterly, 4, 24-3 I. 
O'Mahony, D. (1987). Schoolgirl pregnancies in Libode, Transkei. South African Medical Journal, 71, 771-773.

Petersen, I., Bhagwanjee, A., Parekh, A., Paruk, Z. \& Subedar, H. (1996). Developing primary health care systems in South Africa.' the case of KwaDedangendlale. The Community Mental Health Project, University of Durban-Westville, Durban.

Pitt, L. (1994). Population estimates. Unpublished paper, Valley Trust, Durban.

Preston-Whyte, E. \& Allen, J. (1992). Teenage pregnancy in the Coloured community. In S. Burman \& E. Preston-Whyte (Eds), Questionable issue: illegitimacy in South Africa (pp. 208-225). Cape Town: Oxford University Press.

Preston-Whyte, E. \& Zondi, M. (1992). African teenage pregnancy: whose problem? In S.Burman \& E. Preston-Whyte (Eds), Questionable issue: illegitimacy in South Africa (pp. 226-246). Cape Town: Oxford University Press.

Richardson, R.A., Barbour, N.B. \& Bubenzer, D.L. (1991). Bittersweet connections: informal social networks as sources of support and interference for adolescent mothers. Family Relations, 40, 430-434.

Rip, M.R., Keen, C.S. \& Woods, D.L. (1986). Births and perinatal deaths in Mitchell's Plain. South African Medical Journal, 70, 827-830.

Schlegel, A. \& Barry, H. 111. (! 991 ). Adolescence.' an anthropological inquiry. New York: Free Press.

Seitz, V. \& Apfel, H. (1993). Adolescent mothers and repeated child-bearing: Effects of a schoolbased intervention program. American Journal of Orthopsychiatry, 63, 572-581.

Stavrou, S. \& Luckin, L. (1992). Baseline research survey and community liaison results. Lower Langefonte Community Development Project. Centre for Social and Development Studies, University of Natal, Durban.

Thompson, M.S. \& Peebles-Wilkins, W. (1992). The impact of formal, informal, and societal support networks on the psychological well-being of black adolescent mothers. Social Work, 37 , 322-328.

Viljoen, S. (1994). Strengths and weaknesses in the family life of black South Africans. Cooperative Research Programme on Marriage and Family Life (Report HG/MF-16). Pretoria: Human Sciences Research Council.

By Angina Parekh[*] Department of Psychology, University of Durban-Westville, Private Bag X54001, Durban 4000, South Africa

Cheryl de la Rey Department of Psychology, University of Cape Town, Private Bag, Rondebosch 7700, South Africa

Copyright of South African Journal of Psychology is the property of South African Journal of Psychology and its content may not be copied or emailed to multiple sites or posted to a listserv without the copyright holder's express written permission. However, users may print, download, or email articles for individual use. 